\title{
Diagnosis of antigenic markers of acute toxoplasmosis by IgG avidity immunoblotting
}

\author{
Siamak Ali-Heydari, Hossien Keshavarz, Saeedeh Shojaee* and Mehdi Mohebali \\ School of Public Health, Tehran University of Medical Sciences, Tehran, Iran
}

Received 24 October 2012, Accepted 27 April 2013, Published online 22 May 2013

\begin{abstract}
To perform IgG avidity immunoblotting assay for detection of acute toxoplasmosis, 100 serum samples were collected from Tehran, Iran. The presence of Toxoplasma-specific IgG and IgM antibodies were checked by commercial Trinity kit. Samples were categorized in acute and chronic phases of Toxoplasma gondii infection according to IgG avidity ELISA. IgG avidity immunoblotting was performed, and antigenic bands with molecular weights of 22, 25, $28,30,32,42,44,49,55,60,66,69,88,106,130$ and $157 \mathrm{kDa}$ were recognized as low avidity markers. The most prevalent antigen for low avidity was p22. It is concluded that IgG avidity immunoblotting could distinguish acute and chronic phases of $T$. gondii infection.
\end{abstract}

Key words: toxoplasmosis, avidity immunoblotting.

Résumé - Diagnostic des marqueurs antigéniques de toxoplasmose aigue par immunoréplique d'avidité des IgG. Pour exécuter un essai d'immunoréplique d'avidité des IgG pour la détection de la toxoplasmose aigue, cent échantillons de sérums ont été collectés à Téhéran, Iran. La présence d'anticorps IgG et IgM spécifiques de Toxoplasma a été vérifiée par le kit commercial Trinity. Les échantillons ont été caractérisés comme phases chronique ou aigue d'infection par Toxoplasma gondii en fonction d'avidité ELISA des IgG. Une immunoréplique d'avidité des IgG a été effectuée, et les bandes antigéniques de poids moléculaires de 22, 25, 28, 30, 44, 49, 55, $60,66,69,88,106,130$ et $157 \mathrm{kDa}$ ont été reconnues comme des marqueurs de basse avidité. L'antigène le plus prévalent pour la basse avidité était p22. On conclut que l'immunoréplique d'avidité des IgG pourrait distinguer les phases chroniques ou aigue d'infection par T. gondii.

\section{Introduction}

Toxoplasma gondii is an obligate intracellular parasite that invades the host cell, replicates and finally leads to the lysis of the cell [3]. T. gondii is associated with congenital infection and it can cause encephalitis, or systemic infection in immunocompromised patients [14]. It is important to know whether the infection is recently acquired or is chronic. Differentiation between acute and chronic infection has a dramatic impact, especially for the developing fetus [2]. Maternal infection diagnosis is based on serological methods with detection of specific IgG and IgM antibodies [7]. In some cases, the IgM antibody remains long-lasting. Thus the presence of IgM or IgG antibodies cannot define whether the infection is acute or chronic [11]. The avidity of $T$. gondii antigen to specific antibodies can change during the courses of infection. With this regard, in the acute stages, the avidity is low and increases with the duration of infection [5]. In the IgG avidity ELISA test, protein denaturing agents, such as urea, are used to dissociate the

\footnotetext{
*email: shojaee1980@yahoo.com
}

antigen- antibody complex. The result is determined by using the ratio of optical density of urea-treated and untreated wells. In some individuals, low avidity may persist for one year. It is difficult to interpret the results in the IgG avidity test with the presence of IgM antibody, so low avidity does not mean recent infection in all the patients [13]. In some studies, avidity immunoblotting has been used for detection of antigenic markers of acute or chronic toxoplasmosis $[1,10]$, in which different profiles of antigenic markers could be detected with or without washing with urea.

To distinguish the acute $T$. gondii infection, this study was performed to detect immunological markers by IgG avidity immunoblotting.

\section{Materials and methods}

This study was approved by the Ethical Committee of Tehran University of Medical Science. One hundred serum samples were collected from different laboratories in Tehran, Iran. These referred sera were positive for $T$. gondii-specific 
IgG and IgM antibodies according to indirect immunofluorescent antibody test. In our laboratory the presence of IgM and IgG antibodies were confirmed by $\operatorname{IgG}$ and IgM Trinity kit according to the manufacturer recommendations (Trinity, USA). IgG avidity ELISA was performed and the sera were divided in acute and chronic groups according to the avidity ELISA results.

\section{IgG avidity ELISA}

Tachyzoites of $T$. gondii $\mathrm{RH}$ strain were inoculated intraperitoneally in Balb/c mice. All mice were treated in accordance to the principles of laboratory animal care (Laboratory Animal Care Facility, Standard Operating Procedures, Western Illinois University). Male mice were housed in rooms with temperature of $20-23{ }^{\circ} \mathrm{C}$, with constant humidity $(40-50 \%)$, a $12 \mathrm{~h} \mathrm{light/}$ dark cycle, and were fed with the standard diet and water.

The tachyzoites were collected by performing mice peritoneal washing with sterile normal saline ( $\mathrm{pH} 7.2)$. The exudates were centrifuged at $3,000 \mathrm{~g}$, washed, sonicated $(15 \times 10 \mathrm{~s})$ and finally centrifuged at $4{ }^{\circ} \mathrm{C}$ and $12,000 \mathrm{~g}$ for $1 \mathrm{~h}$. The supernatants were collected and the protein amounts were measured by the Bradford method.

The 96 well micro-titer plates (Nunc, Denmark) were coated with $5 \mu \mathrm{g} / \mathrm{mL}$ of soluble antigens in carbonate-bicarbonate buffer ( $\mathrm{pH}$ 9.6) overnight at $4{ }^{\circ} \mathrm{C}$. Plates were washed for three times with PBST (PBS, $0.05 \%$ tween 20 ), then sera diluted in PBST (1:200) were added in duplicate rows (row A and row B). After incubation for $1 \mathrm{~h}$ at $37{ }^{\circ} \mathrm{C}$, row B was washed three times with PBST, and row A was washed three times with PBST containing $6 \mathrm{M}$ urea and a fourth time with PBST. Then antihuman IgG conjugated with horseradish peroxidase (Dako, Denmark) at the dilution of $1 / 1,000$ in PBST was added and incubated for $1 \mathrm{~h}$, followed by addition of the ortho-phenylendiamidine (OPD), (Merck, Germany) substrate. The reaction was stopped and the absorbance (Abs) was read by an automated ELISA reader (BIOTEC, LX800, USA) at $492 \mathrm{~nm}$. Avidity index (AI; \%) was calculated as the result of Abs of wells washed with PBST containing urea (U+), divided by the Abs of wells washed with PBST (U-), and multiplied with 100 , based on the formula; $\mathrm{AI}=\mathrm{Abs}(\mathrm{U}+) / \mathrm{Abs}\left(\mathrm{U}_{-}\right) \times 100$.

\section{IgG avidity immunoblotting}

The soluble antigens of $T$. gondii RH strain were prepared as mentioned for avidity ELISA. The soluble antigens $(10 \mu \mathrm{g} / \mathrm{well})$, and molecular weight markers (chromatein prestained protein ladder, Vivantis) were run on $12 \%$ polyacrylamide electrophoresis gel at $150 \mathrm{~V}$ for $3 \mathrm{~h}$. The gel was transferred onto nitrocellulose paper (Porablot, Germany) under a current of $50 \mathrm{~mA}$ overnight. The paper was cut, the marker separated, and the strips of paper blocked with 3\% skimmed milk (Merck, Germany) in PBST for $2 \mathrm{~h}$. Each diluted sera $(1: 50)$ in PBST was added in duplicate on nitrocellulose strips. After overnight incubation, one strip was washed with PBST and the other washed with PBST containing $6 \mathrm{M}$ urea for $5 \mathrm{~min}$ three times. The fourth washing was done with PBST for all the strips. Then, the antihuman IgG conjugated with horseradish

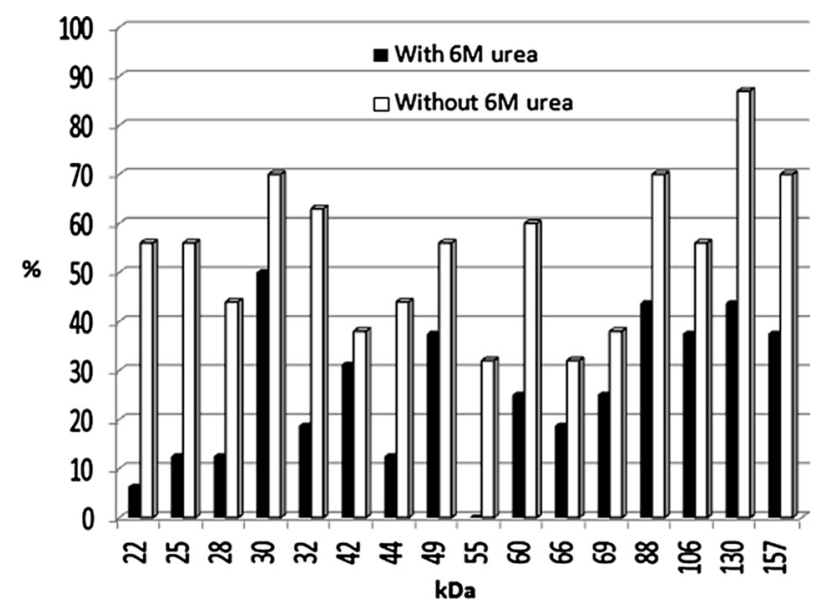

Figure 1. Frequency of antigenic bands after washing without or with $6 \mathrm{M}$ urea in acute phase of $T$. gondii infection by avidity immunoblotting.

peroxidase (HRP) (Dako, Denmark) at the dilution of 1/500 in PBST was added. After incubation for $1 \mathrm{~h}$ and washing for three times the diaminobenzidine (DAB) (Sigma, USA) substrate was added. The reaction was stopped by rinsing of the strips with distilled water. To determine the specificity of avidity immunoblotting, 10 negative sera for Toxoplasma-specific $\mathrm{IgG}$ and $\mathrm{IgM}$ antibodies were tested too.

\section{Results}

According to the Trinity kit from the 100 Toxoplasmaspecific IgG positive sera tested, 23 samples had Toxoplasmaspecific IgM antibody too. According to the results of $\operatorname{IgG}$ avidity ELISA, from the $100 \mathrm{IgG}$ positive sera, 16 samples had $\mathrm{AI} \leq 50$, so were placed in acute phase of infection and 84 samples had AI $>50$ and were placed in chronic phase of infection.

The acute group with $\mathrm{AI} \leq 50$ had shown different antigenic profiles after washing with PBST, containing $6 \mathrm{M}$ urea by IgG avidity immunoblotting. The differences were seen in $22,25,28,30,32,42,44,49,55,60,66,69,88,106,130$ and $157 \mathrm{kDa}$ antigenic bands. The most prevalent difference was seen with the $22 \mathrm{kDa}$ band after washing with PBST containing urea (Figures 1 and 3). In the group with $\mathrm{AI}>50$ the antigenic profile was similar in 77 samples. Seven samples had different antigenic profiles after washing with PBS containing $6 \mathrm{M}$ urea (Figure 2). These seven samples had IgM antibody according to Trinity kit.

No positive reaction was seen in negative sera by avidity immunoblotting.

\section{Discussion}

In order to make a reliable decision about the treatment of T. gondii infection, it should be known whether the infection is in the acute or chronic stage. Thus supplementary methods, which can differentiate between the early and late stage of toxoplasmosis are needed [8]. IgM antibodies are detectable for one year or more, following the acute phase of infection in some 


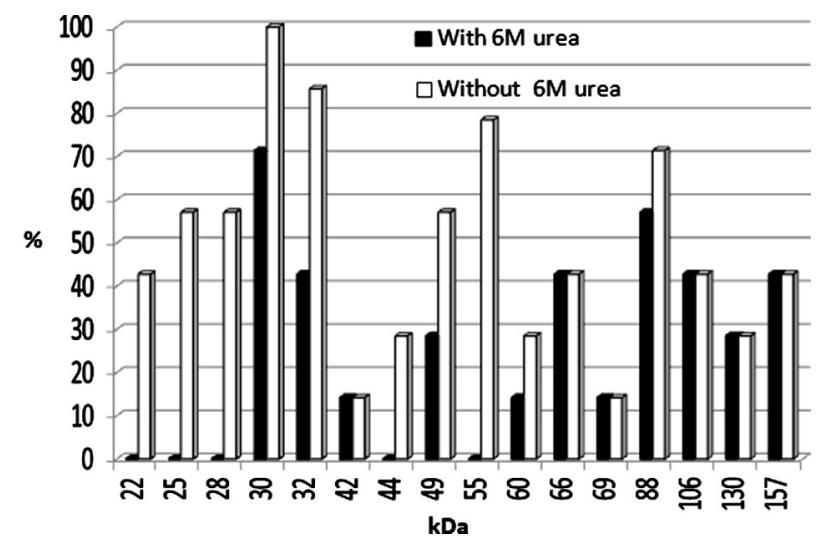

Figure 2. Frequency of antigenic bands after washing without or with $6 \mathrm{M}$ urea in $T$. gondii $\mathrm{IgM}$ positive samples with $\mathrm{AI}>50$ by avidity immunoblotting.

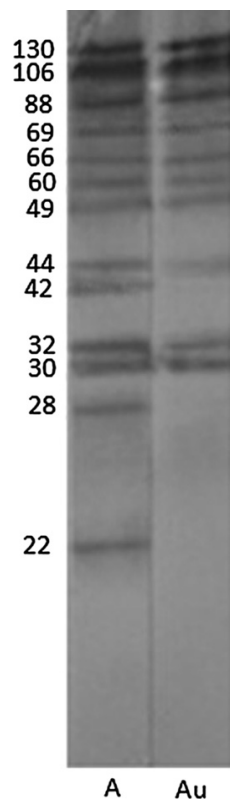

Figure 3. Antigenic bands after washing without or with $6 \mathrm{M}$ urea in $T$. gondii infection by avidity immunoblotting. A: acute phase washed without urea, Au: acute phase washed with urea.

individuals, so the presence of $\operatorname{IgM}$ antibodies is not always an indication of a recent infection [10]. In recent years major efforts have been made improving the ability to diagnose recently acquired infection in the pregnant women and congenital infection in the fetus and newborn. Early detection of anti- $T$. gondii antibody avidity is a valuable and useful tool for identifying positive IgM, particularly in pregnant women. According to the IgG avidity test, high avidity means that the infection has occurred within the 4-5 months before [4, 11-13].

Interpretation of results of $\mathrm{IgG}$ avidity test in presence of IgM antibody is critical because the low avidity may persist up to one year and here, it does not mean the recently acquired infection [9]. By using an immunoblotting method, antigenic markers of acute and chronic phases of T. gondii infection could be characterized [10].

The present study was performed to determine specific antigenic bands in acute and chronic phases of toxoplasmosis. Serum samples were tested for the presence of $T$. gondii IgG and IgM antibodies by a commercial ELISA kit. Then IgG avidity ELISA was performed and samples were divided into two groups: acute group with $\mathrm{AI} \leq 50$ and chronic with $\mathrm{AI}>50$. After performing $\mathrm{IgG}$ avidity immunoblotting, all the samples in acute phase had different antigenic profiles when washed with buffer containing $6 \mathrm{M}$ urea, in comparison to washing with buffer alone.

In this study, antigenic bands with molecular weights of 22 , $25,28,30,32,42,44,49,55,60,66,69,88,106,130$ and $157 \mathrm{kDa}$ were recognized as low avidity markers. The p22, which probably corresponds to SAG2, was present in about $56 \%$ of sera that disappeared in about $50 \%$ of them after washing with $6 \mathrm{M}$ urea, so it seems that the p22 could be a good marker of acute infection in avidity immunoblotting. Araujo and Ferreira (2008) [1] performed IgG avidity immunoblotting against excreted/secreted antigens of $T$. gondii and reported that the $30 \mathrm{kDa}$ antigen was a good marker for acute toxoplasmosis in avidity immunoblotting. In 2011, Habib et al. [6] claimed that the $30 \mathrm{kDa}$ antigen was reactive with almost all sera either in acute or latent phases of infection with high avidity IgG in mice model. They found that, using whole tachyzoite extract in IgG avidity immunoblotting, the bands of 10 and $39 \mathrm{kDa}$ could discriminate between recent and latent stages of $T$. gondii infection in mice. In this study the p30 was washed with PBS containing urea in only $20 \%$ of sera with acute toxoplasmosis. Marcolino et al. (2000) [10] observed that bands p16, p32, p38, p40, p43, p54, p60 and p97 were more frequently recognized by low avidity IgG in recent infection and by high avidity in chronic toxoplasmosis. From these antigenic bands, the p38 was found an optimal antigenic marker of low avidity for recent T. gondii infection due to a significant decrease of its frequency after washing with urea.

In this study all the samples in acute phase of T. gondii infection showed differences in antigenic bands after washing with urea in comparison to washing without urea. Some IgM positive samples that were checked by commercial ELISA kit had IgG avidity index more than 50 (AI > 50). It was interesting that these mentioned sera had different antigenic profiles in avidity immunoblotting when washed with urea, in comparison with washing without urea. These sera divided in chronic group according to avidity ELISA, but they had IgM antibody against T. gondii infection, and they also showed different antigenic profiles in avidity immunoblotting, so the results of avidity immunoblotting and Trinity kit were correlated with each other.

The present study showed that IgG immunoblotting avidity can distinguish acute from chronic phases of $T$. gondii infection defined on the basis of IgG ELISA avidity.

Acknowledgements. This study was done as MSPH thesis in the School of Public Health, Tehran University of Medical Sciences. The authors declare that they have no conflict of interests. The authors wish to thank Miss Roshanak R. Shahsavandi for her assistance. 


\section{References}

1. Araújo PRB, Ferreira AW. 2008. Avidity of IgG antibodies against excreted/secreted antigens of Toxoplasma gondii: immunological marker for acute recent toxoplasmosis. Revista da Sociedade Brasileria de Medicina Tropical, 41, 142-147.

2. Boothroyd JC. 2009. Toxoplasma gondii: 25 years and 25 advances for the field. International Journal of Parasitology, 39, 935-946.

3. Boyle JP, Radke JR. 2009. A history of studies that examine the interactions of Toxoplasma with its host cell: Emphasis on in vitro models. International Journal of Parasitology, 39, 903914.

4. Crucerescu E, Lovin DR. 2002. Study on specific IgG avidity as a tool for recent primary Toxoplasma gondii infection diagnosis. Journal of Preventive Medicine, 10, 56-62.

5. Dubey JP. 2010. Toxoplasmosis of animals and humans. 2nd edn. CRC Press, Taylor \& Francis Group, New York.

6. Habib FSM, Ali NM, El-kadery AA, Soffar SA, Abdel-Razek MG. 2011. Sequential recognition of antigenic markers of Toxoplasma gondii tachyzoite by pooled sera of mice with experimental toxoplasmosis. Parasitology Research, 108, 151-160.

7. Hafid J, Flori P, Raberin H, Tran Manh Sung R. 2001. Comparison of PCR, capture ELISA and immunoblotting for detection of Toxoplasma gondii in infected mice. Journal of Medical Microbiology, 50, 1100-1104.

8. Horvath KN, Szenasi Z, Danka J, Kucsera I. 2005. Value of the IgG avidity in the diagnosis of recent toxoplasmosis: A comparative study of four commercially available anti- Toxoplasma gondii IgG avidity assays. Acta Parasitologica, 50, 255260.

9. Liesenfeld O, Montoya JG, Kinney S, Press C, Remington JS. 2001. Effects of testing for IgG avidity in the diagnosis of Toxoplasma gondii infection in pregnant women: experience in a US reference laboratory. Journal of Infectious Diseases, 183, $1248-1253$.

10. Marcolino PT, Silva DAO, Leser PG, Camargo ME, Mineo JR. 2000. Molecular markers in acute and chronic phases of human toxoplasmosis: Determination of immunogloboling $\mathrm{G}$ avidity by western blotting. Clinical Diagnostic Laboratory Immunology, 7, 384-389.

11. Press C, Montoya JG, Remington JS. 2005. Use of a single serum sample for diagnosis of acute toxoplasmosis in pregnant women and other adults. Journal of Clinical Microbiology, 43, 3481-3483.

12. Rahbari AH, Keshavarz H, Shojaee S, Mohebali M, Rezaeian M. 2012. IgG avidity ELISA test for diagnosis of acute toxoplasmosis in humans. Korean Journal of Parasitology, 50, 99-102.

13. Remington JS, Tulliez P, Montoya JG. 2004. Recent developments for diagnosis of toxoplasmosis. Journal of Clinical Microbiology, 42, 941-945.

14. Weiss LM, Dubey JP. 2009. Toxoplasmosis: A history of clinical observations. International Journal of Parasitology, 39, 895-901.

Cite this article as: Ali-Heydari S, Keshavarz H, Shojaee S \& Mohebali M: Diagnosis of antigenic markers of acute toxoplasmosis by $\mathrm{IgG}$ avidity immunoblotting. Parasite, 2013, 20, 18.

O PARASTE

An international open-access, peer-reviewed, online journal publishing high quality papers on all aspects of human and animal parasitology

Reviews, articles and short notes may be submitted. Fields include, but are not limited to: general, medical and veterinary parasitology; morphology, including ultrastructure; parasite systematics, including entomology, acarology, helminthology and protistology, and molecular analyses; molecular biology and biochemistry; immunology of parasitic diseases; host-parasite relationships; ecology and life history of parasites; epidemiology; therapeutics; new diagnostic tools.

All papers in Parasite are published in English. Manuscripts should have a broad interest and must not have been published or submitted elsewhere. No limit is imposed on the length of manuscripts.

Parasite (open-access) continues Parasite (print and online editions, 1994-2012) and Annales de Parasitologie Humaine et Comparée (1923-1993) and is the official journal of the Société Française de Parasitologie. 